\title{
ЭФФЕКТИВНОСТЬ ПРОВОДИМОЙ РЕГИОНАЛЬНОЙ ПОЛИТИКИ В ОБЛАСТИ ФИЗИЧЕСКОЙ КУЛЬТУРЫ И СПОРТА (НА ПРИМЕРЕ СУБЪЕКТОВ ПРИВОЛЖСКОГО ФЕДЕРАЛЬНОГО ОКРУГА РОССИЙСКОЙ ФЕДЕРАЦИИ)
}

\author{
(c) 2020 Мифтахов Марсель Ринадович \\ Советник Председателя Государственного Совета Республики Татарстан \\ Старший преподаватель кафедры социально-экономических и гуманитарных дисциплин \\ Поволжская государственная академия физической культуры, спорта и туризма, Россия, Казань \\ E-mail: Marsel.Miftahov@tatar.ru
}

Спортивная активность человека - одна из неотъемлемых сторон его жизни, залог его здоровья и активной социальной деятельности. Для реализации эффективной региональной и национальной политики в сфере физкультуры и спорта необходимы количественные оценки влияния спортивной активности населения на социально-экономическое развитие, а также основанные на них инструменты управления.

С точки зрения государства увеличение показателя доли населения систематически занимающейся спортом является одним из ключевых приоритетов Национальной цели Сохранения населения, здоровья и благополучия людей".

В соответствии с Указом Президента Российской Федерации рост вышеуказанного показателя вошел в расширенный перечень критериев оценки глав субъектов Российской Федерации в контексте демографических показателей. В этой связи, исследование спортивной активности населения приобретает особую значимость в целях изучения и рассмотрения эффективных подходов повышения государственного управления в области физической культуры и спорта [5].

В данной работе поставлен вопрос о том, какие модели региональной политики наиболее эффективны для повышения спортивной активности и создании условия для занятий спортом. Относится ли государственная политика в области спорта к оправданным социальным затратам, что в свою очередь можно считать инвестициями в будущее, а повышение спортивной активности населения дает значимый социально-экономический эффект?

Для того чтобы ответить на данные вопросы в статье была поставлена следующая цель: оценить влияние спортивной активности населения на экономический рост российских регионов (на примере Приволжского федерального округа) и подготовить предложения по совершенствованию региональной политики в сфере физкультуры и спорта в России.

Ключевые слова: спорт, региональная политика, экономика, спортивная индустрия, развитие, инвестиции, рейтинг, эффективность, экономический эффект, целевые программы, ключевые показатели, индикаторы, доля занимающихся спортом, спорт.

\section{ВВЕДЕНИЕ}

Победные выступления спортсменов на международной арене поднимают престиж государства и вызывают положительный эмоциональный подъем всех слоев населения. Спорт объединяет, сплачивает и воспитывает патриотов страны. В новой истории России спорт среди других сторон жизни достойно позиционировал себя на самых престижных мировых состязаниях. Спортивная отрасль многогранна и универсальна. Она дает импульс для развития другим направлениям экономики. Поэтому перед госу- дарством стоит задача, чтобы физическая культура и спорт успешно развивались в стране на всех уровнях.

Роль и значение спортивной отрасли, подтверждается высокой оценкой государства, которое вкладывает серьезные денежные средства и в инфраструктуру спорта, и в его популяризацию, в том числе посредством проведения крупных международных спортивных мероприятий на территории России и подготовки спортсменов высших достижений для побед на международной арене. Минспорта Российской феде-

\footnotetext{
* Проект единого плана Правительства Российской Федерации по достижению национальных целей развития Российской Федерации на период до 2024 года и на плановый период до 2030 года
} 
рации проводит большую работу по развитию физической культуры и спорта $[1,4]$. Серьезный потенциал физической культуры и спорта и в экономическом секторе народного хозяйства.

Ранее научным коллективом во главе с профессором, д.э.н Т.В.Краминым и автором статьи исследована экономическая природа такого явления как спортивная активность. Широко рассмотрены вопросы эффективности использования факторов спортивной активности в регионах России [10-15].

В настоящем исследовании планируется рассмотреть эффективность использования бюджетных средств в массовом сегменте сферы физкультуры и спорта с точки зрения сопоставления экономических показателей на неэкономические показатели региона.

ДАННЫЕ, МЕТОДЫ И РЕЗУЛЬТАТЫ ИССЛЕДОВАНИЯ

Рассмотрим примеры проводимой региональной политики по повышению спортивной активности населения по отношению к валовому региональному продукту и объему затрат, выделяемых на физкультуру и спорт на примере 14 субъектов Приволжского федерального округа Российской Федерации (Далее - ПФО).

Данные, указанные в таблице 1 за 2019 год, показывают неоднородность в значении показателей, как по доле систематически занимающихся спортом в общей численности населения, так и по объемам ассигнований, выделяемых на спорт в ПФО. Примечательно сравнение показателей регионов ПФО со средними значения в целом по ПФО и РФ. Если по значению доли систематически занимающихся физической культурой и спортом в общей численности населения большинство регионов (9 из 14) превышают общероссийский показатель, то по экономическим показателям таким как: «Всего израсходовано на физкультуру и спорт на душу населения (руб.)», «Валовый региональный продукт на душу населения (тыс.руб.)» у большинства регионов наблюдается отставание от общероссийского уровня.

Регионы с большой численностью населения, как правило, имеют более высокие экономические показатели, указанные в таблице 1 , чем регионы с малой численностью. Первые 5 регионов по уровню ВРП на душу населения такие как: Республика Татарстан, Оренбургская область, Пермский край, Самарская область, Ни- жегородская область располагают 51\% всей численности населения ПФО.

Сгруппируем регионы по 4 подгруппам:

I подгруппа «Опережающее развитие» - peгионы, которые имеют высокий показатель спортивной активности населения при относительно невысоком уровне ВРП на душу населения или уровне затрат на спорт;

II подгруппа «Сбалансированное лидерство»- регионы, которые имеют высокий уровень ВРП на душу населения, уровень затрат на спорт и спортивную активность населения;

III подгруппа «Запаздывающее развитие»регионы, показывающие высокий уровень ВРП на душу населения, уровень затрат на спорт при низком уровне спортивной активности;

IV подгруппа «Сбалансированное отставание» - регионы, имеющие низкий уровень ВРП на душу населения, уровень затрат на спорт и слабый показатель спортивной активности населения.

Распределим регионы Приволжского Федерального округа Российской Федерации с учетом их затрат на физкультуру и спорт и экономического потенциала к уровню показателя спортивной активности населения в соответствии с рисунком 1.

Рассмотрим отношение уровня ВРП на душу населения к уровню показателя спортивной активности населения (рис. 2).

\section{ВЫВОДЫ}

1. Регионы с малой численностью населения ПФО при высоком показателе спортивной активности населения более рационально используют средства в целях привлечения к занятиям физической культурой и спортом (Республика Мордовия, Чувашская Республика, Пензенская область, Республика Марий Эл и Ульяновская область).

2. Удмуртская республика, Пермский край, Нижегородская область, Самарская область, несмотря на высокий уровень ВРП на душу населения, уровень затрат на спорт, слабое внимание уделяют спортивной активности населения;

3. Верхняя группа регионов (II, III квадранты) - имеющая высокий уровень ВРП на душу населения, как правило, регионы с большей численностью населения направляют больше средств для повышения спортивной активности населения;

4. Саратовская область и Кировская об- 
Таблица 1. Сравнительные показатели социально-экономического развития регионов Приволжского Федерального округа Российской Федерации в области физической культуры и спорта в 2019 г. [7,8]

\begin{tabular}{|c|c|c|c|c|c|c|c|c|c|c|}
\hline Регионы ПФО & 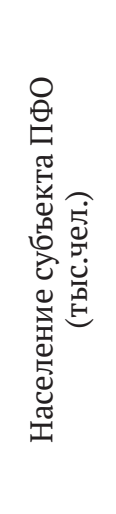 & 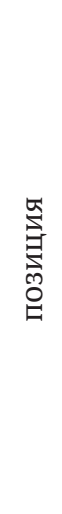 & 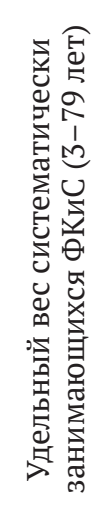 & 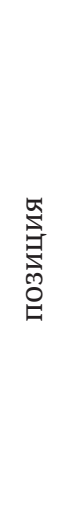 & 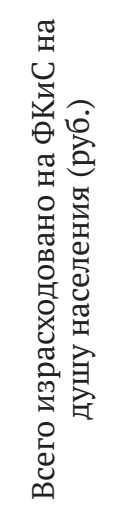 & 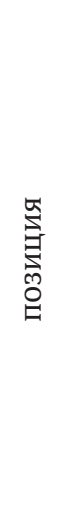 & 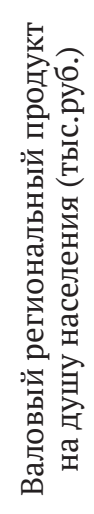 & 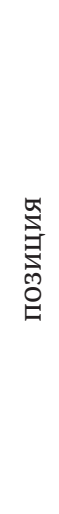 & 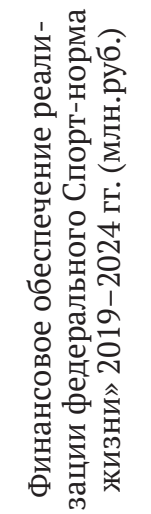 & 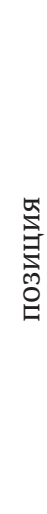 \\
\hline $\begin{array}{c}\text { Республика } \\
\text { Башкортостан }\end{array}$ & 4038,1 & 1 & $45,2 \%$ & 5 & 3578,9 & 1 & 414,5 & 7 & 562,8 & 5 \\
\hline $\begin{array}{c}\text { Республика } \\
\text { Марий Эл }\end{array}$ & 679,4 & 14 & $44,4 \%$ & 7 & 1042,2 & 13 & 261,5 & 13 & 142,7 & 14 \\
\hline $\begin{array}{c}\text { Республика } \\
\text { Мордовия }\end{array}$ & 790,2 & 13 & $45,1 \%$ & 6 & 1873,1 & 10 & 287,6 & 11 & 235,3 & 13 \\
\hline $\begin{array}{c}\text { Республика } \\
\text { Татарстан }\end{array}$ & 3902,9 & 2 & $49,5 \%$ & 1 & 2590,8 & 4 & 632,6 & 1 & 806,2 & 3 \\
\hline $\begin{array}{l}\text { Удмуртская } \\
\text { республика }\end{array}$ & 1501 & 8 & $39,1 \%$ & 14 & 3060,4 & 3 & 420,4 & 6 & 654,1 & 4 \\
\hline $\begin{array}{l}\text { Чувашская } \\
\text { Республика }\end{array}$ & 1217,8 & 12 & $46,8 \%$ & 3 & 1984,8 & 9 & 244,5 & 14 & 326,2 & 9 \\
\hline Пермский край & 2599,3 & 5 & $39,7 \%$ & 11 & 2547,3 & 6 & 507,2 & 3 & 256,5 & 10 \\
\hline $\begin{array}{c}\text { Кировская } \\
\text { область }\end{array}$ & 1262,4 & 10 & $39,6 \%$ & 12 & 1199,7 & 12 & 263,5 & 10 & 242,5 & 11 \\
\hline $\begin{array}{c}\text { Нижегородская } \\
\text { область }\end{array}$ & 3203 & 3 & $41,6 \%$ & 10 & 2399,9 & 7 & 429,6 & 5 & 995,5 & 2 \\
\hline $\begin{array}{c}\text { Оренбургская } \\
\text { область }\end{array}$ & 1956,8 & 7 & $48,3 \%$ & 2 & 1894,7 & 8 & 511,3 & 2 & 224,2 & 12 \\
\hline $\begin{array}{c}\text { Пензенская } \\
\text { область }\end{array}$ & 1305,6 & 9 & $46,4 \%$ & 4 & 1495,5 & 11 & 306,7 & 8 & 511,7 & 6 \\
\hline $\begin{array}{c}\text { Самарская } \\
\text { область }\end{array}$ & 3179,5 & 4 & $42,4 \%$ & 9 & 3250,0 & 2 & 475 & 4 & 1637,6 & 1 \\
\hline $\begin{array}{c}\text { Саратовская } \\
\text { область }\end{array}$ & 2421,9 & 6 & $39,3 \%$ & 13 & 665,2 & 14 & 294,1 & 9 & 386,9 & 8 \\
\hline $\begin{array}{c}\text { Ульяновская } \\
\text { область }\end{array}$ & 1229,8 & 11 & $44,4 \%$ & 8 & 2555,6 & 5 & 282,9 & 12 & 496,4 & 7 \\
\hline ПФО & \multicolumn{2}{|c|}{29287,7} & $43,8 \%$ & (9) & 2401,4 & (7) & 425,7 & (6) & 7478,6 & \\
\hline $\begin{array}{l}\text { Российская } \\
\text { Федерация }\end{array}$ & \multicolumn{2}{|c|}{146748,6} & $43 \%$ & (9) & 5096,6 & (1) & 579 & (2) & 29903,20 & \\
\hline
\end{tabular}




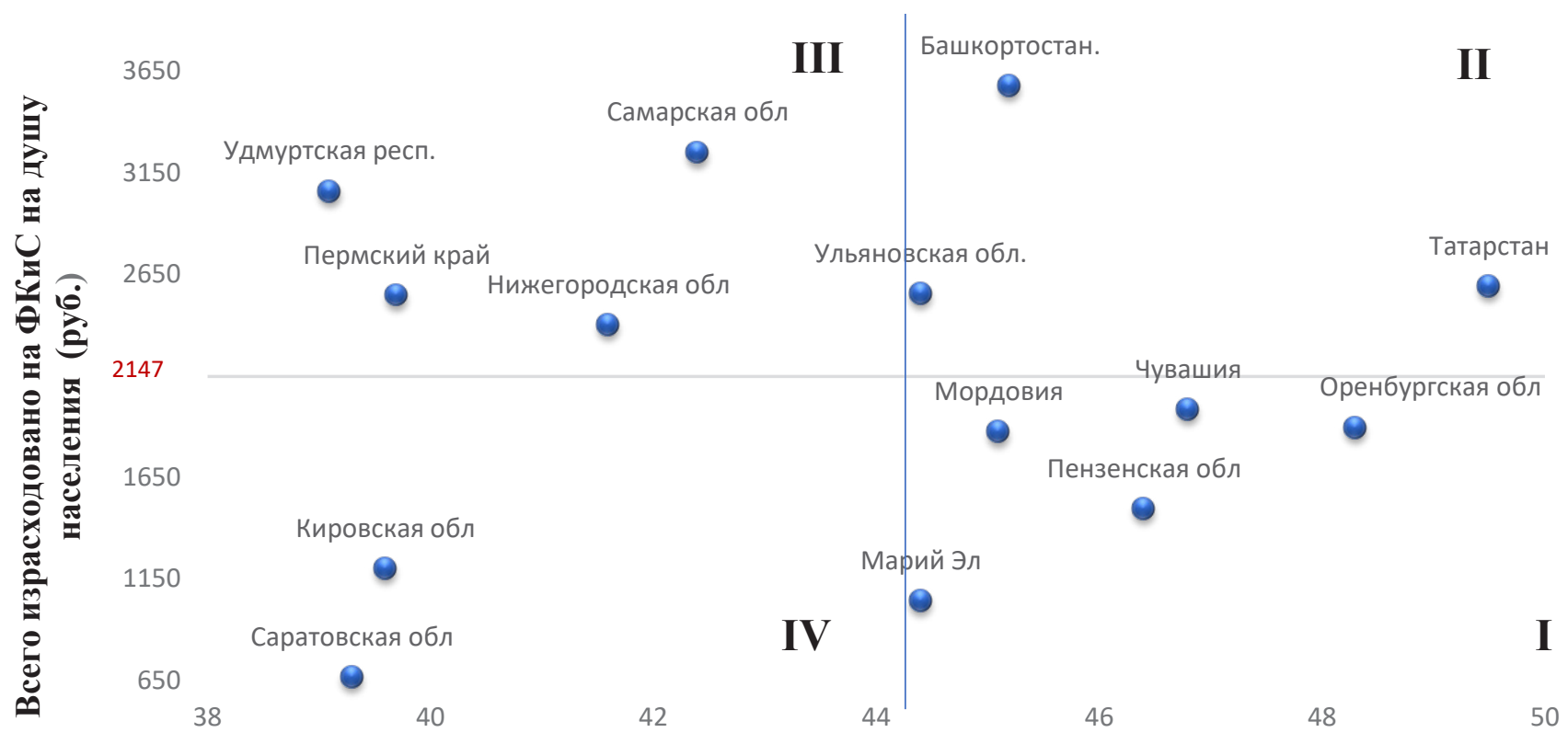

Спортивная активность населения (\%)

Рисунок 1. Матрица распределения регионов Приволжского Федерального округа Российской Федерации с учетом их затрат на физкультуру и спорт к уровню показателя спортивной активности населения

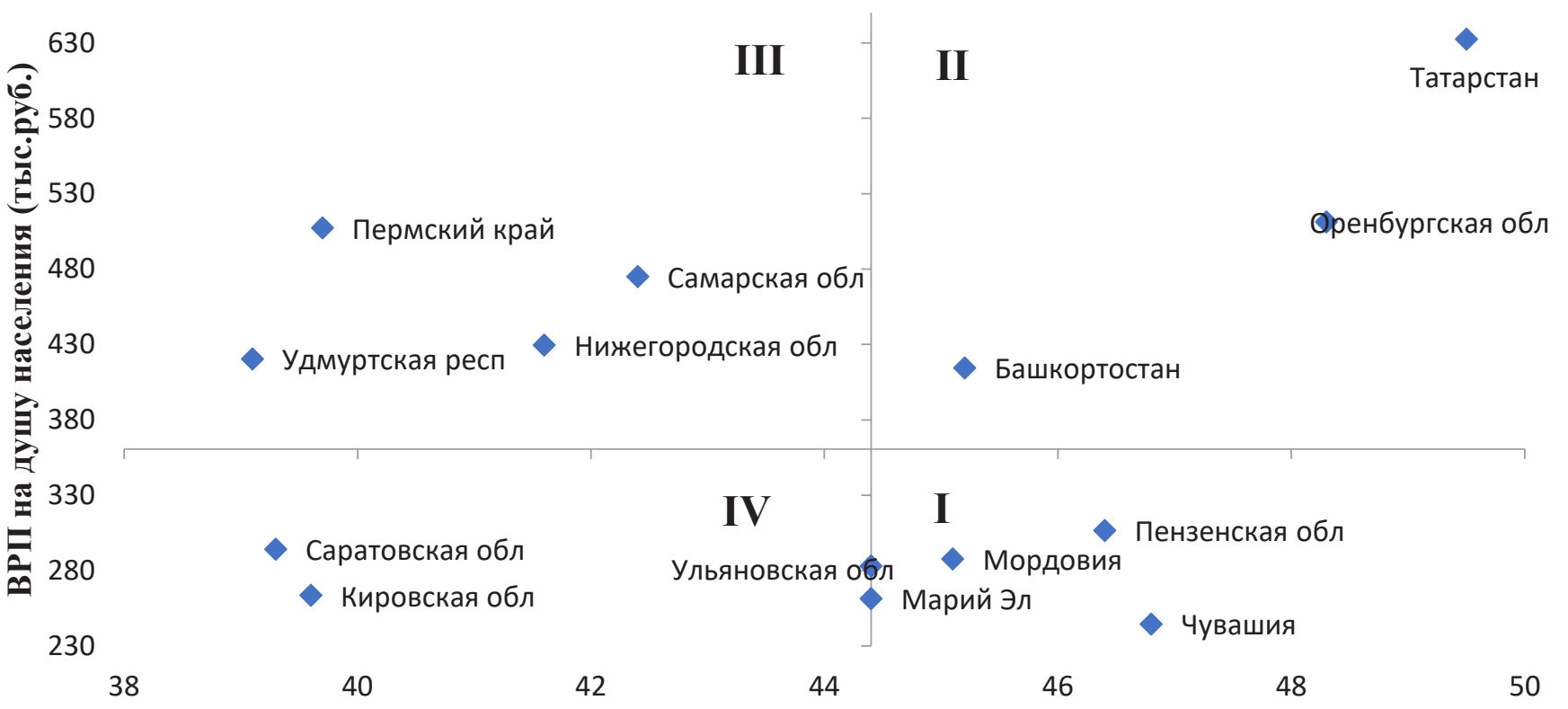

Спортивная активность населения (\%)

Рисунок 2. Матрица распределения субъектов Приволжского Федерального округа Российской Федерации по отношению уровня ВРП на душу населения к уровню показателя спортивной активности населения 
ласть - наиболее отсталые регионы по отношению уровня ВРП на душу населения, затрат на физкультуру и спорт к уровню показателя спортивной активности населения.

5. Ульяновская область, несмотря на высокий показатель расходования средств на физкультуру и спорт на душу населения, не показывает высокий показатель спортивной активности населения;

6. Республика Татарстан - регион, который имеет самый высокий показатель спортивной активности населения при высоком уровне ВРП на душу населения и среднем уровне затрат на спорт;

7. Чувашская республика и Оренбургская область - регионы, показывающие высокий уровень спортивной активности населения при среднем уровне ВРП на душу населения и среднем уровне затрат на спорт.

Для того чтобы дать характеристику региональной политике по повышению спортивной активности рассмотрим полученные выводы с точки зрения сравнения успешных и менее успешных регионов по ряду количественных социально-экономических показателей.

Ранее нами исследовано, что «спортивная активность населения определяется многими индивидуальными материальными и нематериальными факторами, среди которых пол, возраст, социальное окружение, уровень дохода, уровень образования и др.».

Основными социально-экономическими индикаторами, оказывающих воздействие на спортивную активность являются:

1) единовременная пропускная способность объектов спорта;

2) количество спортивных сооружений на 100 тыс. человек населения;

3) расходы на развитие физической культуры и спорта на душу населения;

4) обеспеченность спортивной инфраструктурой в соответствии с социальными нормативами;

5) количество населения на одного штатного работника физической культуры и спорта в разрезе субъектов Российской Федерации;

6) среднедушевые денежные доходы населения.

Достижение высоких значений показателей вышеуказанных факторов, влияющих на уровень спортивной активности будет свидетельствовать об эффективности проводимой региональной политики субъектами страны по повышению уровня спортивной активности населения и формирования здорового образа жизни в обществе.

Рассмотрим примеры региональных политик по повышению показателя спортивной активности среди отдельных субъектов по уровню благосостояния на основе предложенных материальных факторов.

В соответствии с полученной группировкой регионов согласно рисунка 2 объединим подгруппы II и III в группу «Благополучные регионы» сравним Республику Татарстан и Нижегородскую область и в группах I и IV «Запаздывающие регионы» рассмотрим Саратовскую область и Чувашскую республику (табл. 2).

\section{ОБСУЖДЕНИЕ РЕЗУЛЬТАТОВ ИССЛЕДОВА-} НИЯ

В результате сравнительного анализа, в соответствии с таблицей 2 получены следующие выводы:

1. Одним из основных факторов, влияющих на увеличение спортивной активности населения является доступная спортивная инфраструктура. Мы выделяем 3 показателя (№ строки 2,3,5), характеризующий доступность спортивной инфраструктуры это: единовременная пропускная способность объектов спорта от норматива\%; количество спортивных сооружений на 100 тыс. человек населения (единиц); обеспеченность спортивной инфраструктурой в соответствии с социальными нормативами чел. (факт/норма).

В соответствии с таблицей 2 мы видим значительное опережение по всем 3 показателям ранее выявленных успешных республики Татарстан и Чувашии. Также можно отметить, что показатели в Чувашии выше Татарстана ввиду малой численности населения и менее урбанизированной структуры региона. Обеспеченность спортивной инфраструктурой в соответствии с социальными нормативами Нижегородской и Саратовской области можно отметить как недостаточную. Единовременная пропускная способность объектов спорта от социальных нормативов в Нижегородской области ниже общероссийского и ПФО. Региону необходимо рассмотреть возможность ввода крупных спортивных объектов, в том числе в рамках федеральных проектов и программ, таких как федеральный проект «Спорт - норма жизни». По финанси- 
Таблица 2. Сравнение основных социально-экономических показателей, оказывающих влияние на спортивную активность регионов ПФО в Российской Федерации $[7,8]$

\begin{tabular}{|c|c|c|c|c|c|}
\hline \multirow[b]{2}{*}{ № } & \multirow{2}{*}{$\begin{array}{l}\text { Материальные факторы } \\
\text { спортивной активности }\end{array}$} & \multicolumn{2}{|c|}{ «Благополучные регионы» } & \multicolumn{2}{|c|}{ «Запаздывающие регионы» } \\
\hline & & $\begin{array}{c}\text { Нижегородская } \\
\text { область }\end{array}$ & $\begin{array}{c}\text { Республика } \\
\text { Татарстан }\end{array}$ & $\begin{array}{l}\text { Саратовская } \\
\text { область }\end{array}$ & $\begin{array}{c}\text { Чувашская } \\
\text { республика }\end{array}$ \\
\hline 1 & $\begin{array}{l}\text { Удельный вес систематически за- } \\
\text { нимающихся ФКиС (3-79 лет) }\end{array}$ & $41,6 \%$ & $49,5 \%$ & $39,3 \%$ & $46,8 \%$ \\
\hline 2 & $\begin{array}{l}\text { валовый региональный продукт на } \\
\text { душу населения, (тыс.руб.) }\end{array}$ & 429,6 & 632,6 & 294,1 & 244,5 \\
\hline 3 & $\begin{array}{l}\text { единовременная пропускная } \\
\text { способность объектов спорта от } \\
\text { норматива, \% }\end{array}$ & 55,9 & 67,1 & 64,8 & 78,8 \\
\hline 4 & $\begin{array}{l}\text { количество спортивных сооруже- } \\
\text { ний на } 100 \text { тыс. человек населения } \\
\text { (единиц) }\end{array}$ & 232,4 & 306,8 & 184,0 & 402,3 \\
\hline 5 & $\begin{array}{l}\text { расходы на развитие физической } \\
\text { культуры и спорта на душу населе- } \\
\text { ния, руб. }\end{array}$ & 2399,9 & 2590,8 & 665,2 & 1984,8 \\
\hline 6 & $\begin{array}{l}\text { обеспеченность спортивной ин- } \\
\text { фраструктурой в соответствии с } \\
\text { социальными нормативами чел. } \\
\text { (факт/норма), чел. }\end{array}$ & $202844 / 362624$ & $295026 / 439937$ & $179301 / 276892$ & $109134 / 138440$ \\
\hline 7 & $\begin{array}{l}\text { численность населения на одного } \\
\text { штатного работника физической } \\
\text { культуры и спорта в разрезе субъек- } \\
\text { тов Российской Федерации }\end{array}$ & 366,4 & 414,5 & 433,4 & 495,4 \\
\hline 8 & $\begin{array}{l}\text { Среднедушевые денежные доходы } \\
\text { (в месяц), руб. }\end{array}$ & 33805 & 35686 & 22752 & 20167 \\
\hline
\end{tabular}

рованию в рамках данного проекта область расположена на 2 месте в ПФО. Немаловажное значение имеет работа по получению права и подготовки к проведению крупных спортивных мероприятий с финансовым обеспечением соответствующей спортивной инфраструктуры по примеру Республики Татарстан, Свердловской области, Краснодарского края, Сахалинской области.

2. Не менее актуальными в привлечении населения к систематическим занятиям к спорту являются финансовые факторы, влияющие на результаты региональной политики по повышению спортивной активности населения. Для сравнения рассмотрим строки № 2,5,8. Республика Татарстан является наиболее развитым регионом по отношению к Нижегородской области с точки зрения ВРП и удельного веса занимающихся спортом, вместе с тем уступает по показателям расходов на развитие физической культуры и спорта на душу населения и среднедушевых денежных доходов (в месяц). Это свидетельствует о тех формах и практиках мотивирования населения к спорту, которые реализуются в Татарстане без привлечения большего объема финансовых ресурсов (например, популярность спорта среди населения, развитие общественных пространств, строительство малобюджетных плоскостных спортивных объектов по месту жительства, проведение любительских соревнований и корпоративных лиг).

Несмотря на низкий уровень валового регионального продукта (14-й в округе) и среднедушевых денежных доходов населения, Чувашская республика показывает один из лучших в Приволжском федеральном округе (3) показателей удельного веса занимающихся физической культурой и спортом и рассматривается в качестве лучших региональных практик привлечения населения к занятиям спортом. Это обуславливается высокой обеспеченностью спортивными сооружениями в регионе, наличием профессионального кадрового состава учреждений физической культуры и спорта, а также высокой популярностью традиционных массовых видов спорта в регионе (легкая атлетика, лыжные гонки, плавание). Саратовская область наименее обеспечена финансированием как в части затрат на физкультуру и спорт на душу населения, так и на финансовое обеспечение реализации федерального проекта Спорт-норма жизни» на 2019-2024 гг. 
3. Количество населения на одного штатного работника физической культуры и спорта в разрезе субъектов Российской Федерации свидетельствует о потребности Нижегородской области в обеспечении спортивной отрасли профессиональными кадровыми ресурсами. Также можно отметить в группе «Запаздывающие регионы» общий уровень обеспеченности кадрами выше, чем в «Благополучных регионах» это говорит о необходимости увеличения профессионального кадрового состава Нижегородской области и Республики Татарстан в соответствие с нормативами распоряжения Правительства РФ от 03.07.1996 № 1063-р и численностью населения вышеуказанных регионов.

\section{ЗАКЛЮЧЕНИЕ}

Таким образом, в ходе исследования выявлены основные подходы по повышению региональной спортивной политики. Мы выделяем модель благополучных регионов, где большое внимание уделяется созданию условий для занятий спортом, вкладываются средства в спортивную инфраструктуру, финансирование профессиональных команд и проведение крупных спортивных мероприятий (Татарстан, Башкортостан). Такая модель дает быстрый эффект по росту показателя спортивной активности, повышает имидж региона, привлекательна для привлечения, но несет большие затраты для регионов и федерального центра.

Одновременно есть модель реализации региональной спортивной политики для не богатых регионов, таких как Чувашская республика, Оренбургская область. Основной особенностью, которой является эффективное использование имеющейся спортивной инфраструктуры, популяризация видов спорта не нуждающихся в дорогих спортивных объектах (бег, лыжные гонки, скандинавская ходьба, триатлон). Высокий уровень профессионального кадрового состава, работающего с населением, развитие недорогих форм физкультурно-оздоровительной деятельности (воркаут, кроссфит).

Оптимальной представляется смешанная модель развития региональной спортивной политики с привлечением лучших практик субъектов ПФО. В которую должны войти следующие направления работы:

- организация физкультурных и спортивных мероприятий для всех категорий и групп населения;
- реализация Всероссийского физкультурно-спортивного комплекса «Готов к труду и обороне» (ГТО);

- повышение доступности услуг в сфере физической культуры и спорта, предоставляемых населению;

- стимулирование физкультурно-спортивной работы по месту жительства и трудовой деятельности, включая предоставление грантовой поддержки организациям, реализующим проекты в сфере физической культуры и массового спорта;

Большое значение в развитии физкультуры и спорта в регионах России имеет программноцелевой подход. С 2019 года начал реализоваться федеральный проект «Спорт - норма жизни», основная цель которого достижение систематически занимающихся физкультурой и спортом населения к 2024 году до 55\% от общего количества населения. Во всех субъектах ПФО разработаны и реализуются региональные составляющие федерального проекта «Спорт - норма жизни». Значения показателя охвата населения систематическим занятием спортом для субъектов ПФО определены федеральным проектом «Спорт - норма жизни».

Общий объем финансирования в 2019 году региональных проектов «Спорт - норма жизни» в ПФО превысил 4100 млн. руб. (свыше 1990 млн. федеральный бюджет, более 1500 млн. рублей региональные бюджеты). Объем финансирования бюджетов всех уровней за 6 лет реализации проекта составит 7478,6 млн.руб или $25 \%$ от общей суммы финансирования проекта в Российской Федерации.

Дальнейшая реализация проекта позволит достичь показателей, обозначенных в национальном проекте Спорт - норма жизни, создать дополнительные инфраструктурные условия, как для развития массового спорта, так и для подготовки спортивного резерва сборных команд регионов ПФО, стабильной качественной подготовки спортсменов.

С учетом проведенного анализа выявлены регионы, которые недополучают финансирование в рамках вышеуказанного проекта, несмотря на высокую эффективность своей работы (Чувашская республика, Оренбургская область, Республика Мордовия). Министерству спорта РФ необходимо пересмотреть финансирование проекта «Спорт - норма жизни» в отношении этих регионов. 


\section{Библиографический список}

1 Федеральный закон от 04.12.2007 № 329-Ф3 «О физической культуре и спорте в Российской Федерации»

2 Федеральный закон от 29.12.2012 N 273-Ф3 «Об образовании в Российской Федерации»

3 Федеральный закон от 06.10.2003 N 131-Ф3 «Об общих принципах организации местного самоуправления в Российской Федерации»

4 Указ Президента Российской Федерации от 7 мая 2018 г. № 204 «О национальных целях и стратегических задачах развития Российской Федерации на период до 2024 года»

5 Указ Президента Российской Федерации от 4 февраля 2021 г. № 68 «Об оценке эффективности деятельности высших должностных лиц (руководителей высших исполнительных органов государственной власти) субъектов Российской Федерации и деятельности органов исполнительной власти субъектов Российской Федерации».

6 «Регионы России. Социально-экономические показатели»: ежегодные отчеты Федеральной службы государственной статистики.- URL: http://www.gks.ru/free_doc/new_site/region_stat/sep_region.html (дата обращения: 15.01.2021).

7 Краткий статистический сборник «Россия в цифрах». 2020:. / Росстат- М., - 550 с. Стр. 40-62. file://C:/Users/ MDMS/Downloads/Rus_2020\%20(1).pdf; - (дата обращения: 20.12.2020).

8 Показатели для оценки эффективности деятельности органов исполнительной власти субъектов Российской Федерации: ежегодные отчеты Министерства спорта Российской Федерации.- URL: https://www. minsport.gov.ru/sport/physical-culture/statisticheskaya-inf (дата обращения: 15.01.2021).

9 Показатели развития физической культуры и спорта в разрезе субъектов Российской Федерации: ежегодные отчеты Министерства спорта Российской Федерации.- URL: https://minsport.gov.ru/sport/physicalculture/statisticheskaya-inf/ (дата обращения: 15.01.2021).

10 Мифтахов М.Р. Роль спортивной активности в развитии социально-экономических систем // Вестник Алтайской академии экономики и права.-2020. - № 11 (часть 2) - C. 289-294; URL: http://vaael.ru/ru/article/ view?id=1423

11 Мифтахов М.P. Совершенствование критериев оценки эффективности реализации программ развития физической культуры и спорта (На примере Республике Татарстан) // Вестник Алтайской академии экономики и права. - 2020. - № 11 (часть 1) - C. 92-99; URL: http://vaael.ru/ru/article/view?id=1399

12 Мифтахов, M.P. Спортивная активность населения как фактор экономического роста региона (на примере г. Казани) / М. Р. Мифтахов, М. М. Бариев, Т. В. Крамин // Теория и практика физической культуры.-2017.№ 5.- C. 49-52.

13 Мифтахов, М.Р. Социально-экономическая эффективность повышения спортивной активности населения (на примере Республики Татарстан) / М.Р. Мифтахов, Т.В.Крамин // Проблемы анализа и моделирования региональных социально-экономических процессов: сборник трудов VII Международной научнопрактической конференции.- Казань, 2017.- С. 102-106.

14 Мифтахов, М.Р. Социально-экономические аспекты эффективности государственной политики по повышению спортивной активности населения / М. Р. Мифтахов, Т.В. Крамин, М. М.Бариев // Культура физическая и здоровье.-2017.- № 4 (64).- С. 37-42.

15 Kramin T.V., Miftahov M.R., Andreff W., Eroshkina S. B. Social and Economic Factors of Sports Activity in Russian Regions. Сборник статей Международной конференции «Евразия: устойчивое развитие, безопасность, сотрудничество», Самара, 25-26 октября 2019 г.

16 Фахрутдинова Е.В., Ягудин Р. Х., Рыбкин Л. И. Проблемы взрослого населения Республики Татарстан: медикодемографический аспект// Вопросы экономики и права. 2016. № 102. С. 64-68.

17 Ягудин Р.Х., Краснова О.М., ФахрутдиноваЕ.В., РыбкинЛ.И., Рыбкина Н.Л., Краснов А.Е. Некоторые актуальные медико-демографические проблемы городского и сельского населения Республики Татарстан в XXI веке (2001-2016 ГГ.)// Экономический вестник Республики Татарстан. 2017. № 4. С. 29-40. 